\title{
ESTRUTURAS DE OPORTUNIDADE POLÍTICA E ENGAJAMENTO EM ORGANIZAÇÕES DA SOCIEDADE CIVIL: UM ESTUDO COMPARADO SOBRE A AMÉRICA LATINA
}

\author{
Lucio R. Rennó
}

\begin{abstract}
RESUMO
O artigo testa duas explicações teóricas distintas sobre o ativismo cívico na América Latina usando dados nos niveis individual e agregado. Variáveis que operacionalizam conceitos-chave da teoria do capital social são incluidas em um modelo multivariado que também incorpora indicadores empíricos da idéia de "estruturas de oportunidade política" de Tarrow. O primeiro conjunto de variáveis enfoca o papel de variáveis como confiança interpessoal e tolerância na propensão de participação em associações da sociedade civil. O segundo conjunto de variáveis centra-se nos incentivos criados por instituições formais do Estado para a ação coletiva na sociedade. Os dados da América Latina indicam que o arcabouço institucional de um país exerce papel mais decisivo na participação de cidadãos em associações da sociedade civil do que o capital social.
\end{abstract}

PALAVRAS-CHAVE: associativismo; capital social; estruturas de oportunidade política.

\section{INTRODUÇÃO}

O objetivo deste artigo é aplicar duas teorias, aparentemente rivais, sobre o envolvimento de cidadãos em distintas organizações políticas e sociais, lançando mão de dados da América Latina. A meta é simples: testar o impacto de algumas variáveis explicativas, usando um modelo estatístico multivariado em indicadores de participação em distintas formas de associações da sociedade civil organizada. Embora a maior parte das variáveis sejam medidas em nível individual, com dados de pesquisas de opinião pública - mais especificamente a rodada de 1996 do Latinobarômetro - o modelo também incorpora medidas agregadas em nível nacional que foram acrescentadas ao banco de dados do Latinobarômetro. Tais medidas visam justamente a acrescentar a um modelo estatístico, que em sua essência é principalmente inspirado pela teoria do capital social, pressupostos da teoria das estruturas de oportunidade política proposta por Sidney Tarrow (1994; 1996).

O modelo testado leva em consideração tanto os limites e incentivos externos impostos à participação de cidadãos em organizações da sociedade civil (estruturas de oportunidade política), quanto o impacto de predisposições psicológicas individuais na participação em organizações sociais e políticas. Em suma, contextos institucionais criam redes de incentivos e restrições à participação em distintas formas de ação coletiva que não podem ser ignoradas (NORTH, 1995; ROTHSTEIN, 2000) - não são só motivações pessoais, como supõe grande parte da literatura sobre capital social, que afetam decisões individuais sobre o envolvimento com entidades da sociedade civil.

Na próxima seção será descrita a base de dados utilizada. Posteriormente serão discutidas as diferenças existentes entre os grupos e movimentos da sociedade civil analisados aqui. Em seguida apresentar-se-ão os pressupostos da teoria do capital social, que enfoca principalmente aspectos subjetivos do engajamento cívico, e do conceito de estrutura de oportunidade política; em ambos os casos, hipóteses empiricamente verificáveis serão derivadas da teoria. Por último os dados serão analisados e conclusões provisórias propostas.

\section{BANCO DE DADOS}

Os dados utilizados na análise são predominantemente oriundos da série de pesquisas de opinião pública que acontecem anualmente em 
17 países da América Latina sob a coordenação da Corporación Latinobarómetro, sediada na Espanha, e pela Market and Opinion Research International, sediada no Chile. Os dados usados aqui são provenientes da rodada de 1996, com amostras nacionais variando entre 517 e 1200 observações, em um total de 18 516. De acordo com Marta Lagos (1997), coordenadora do projeto, a maior parte do financiamento provém da União Européia por meio do Centro de Investigación, Promoción y Cooperación Internacional (CIPIE) em Madri e do Programa de Desenvolvimento das Nações Unidas.

Na presente análise, o banco de dados de 1996 do Latinobarômetro foi ponderado para corrigir o número desigual de observações por país e foi ajustado para melhor refletir níveis educacionais em cada país segundo a publicação World Development Indicators 1998, do Banco Mundial. No Latinobarômetro de 1996, indivíduos com nível educacional mais alto foram sobre-representados; para corrigir tal distorção, aplicou-se um peso que artificialmente reduz o número de casos com nível educacional mais alto e dá um peso maior aos casos com nível educacional mais baixo. Além disso, foram acrescentados ao banco de dados indicadores nacionais referentes a distintos aspectos da história e do arcabouço institucional desses países ${ }^{1}$.

\section{DISTINÇÕES ENTRE FORMAS ALTER- NATIVAS DE MOBILIZAÇÃO COLETIVA}

O Latinobarômetro 1996 contém vários e distintos indicadores de participação nas mais variadas formas de grupos sociais e políticos. Buscou-se explicar os correlatos da participação em quatro tipos de organização da sociedade civil. Justifica-se estudar esses quatro tipos distintos de mobilização social separadamente e não em um índice aditivo único porque tais formas de ativismo social e político têm não só objetivos diferentes, mas também formas variadas de recrutamento e estratégias distintas de ação. Participação em movimentos e grupos sociais diferentes não podem ser consideradas como um fenômeno social único, e, portanto, combinadas indiscriminadamente em um único indicador. Tais entidades podem servir para mediar demandas

\footnotetext{
1 Todas as variáveis utilizadas na análise são descritas no "Apêndice".
}

políticas e sociais antagônicas, assim como envolver uma miríade de estilos distintos de mobilização.

A primeira forma de engajamento em ação coletiva analisada é a participação em associações de âmbito nacional, com claros objetivos políticos e voltadas para a defesa de interesses específicos: partidos políticos e sindicatos. Ambas as organizações participam diretamente do conflito político em nível nacional e são voltadas para a disputa alocativa de recursos; são, por excelência, instrumentos de mediação de interesses coletivos organizados.

A segunda variável dependente analisada indica a participação em grupos sociais locais, como grupos de mães, associações de bairro e grupos de igreja. Essas formas de participação têm em comum um escopo mais limitado em suas demandas do que partidos políticos e sindicatos e são voltadas para temas locais e não nacionais ou de classe. Tais organizações não são necessariamente vinculadas a assuntos políticos; são muito mais voltadas para problemas do dia-adia do que para grandes debates nacionais e servem principalmente para formar uma rede de proteção e conforto a seus membros em relação aos acontecimentos cotidianos.

Ambas as formas de ação coletiva mencionadas acima já foram exaustivamente estudadas nas ciências sociais e são vistas como formas tradicionais de engajamento cívico (ALMOND \& VERBA, 1981; VERBA, SCHLOZMAN \& BRADY, 1996). Contudo, há também medidas no Latinobarômetro voltadas para a participação em formas não tão tradicionais de ação coletiva. Duas dessas serão analisadas: participação em novos movimentos sociais (TOURRAINE, 2000) e em protestos políticos (LEVINE \& MAINWARING, 1994).

O terceiro tipo de mobilização estudado é a participação em movimentos ambientalistas. Os novos movimentos sociais desse tipo, como aponta Tourraine, têm uma lógica de atuação distinta da dos movimentos sociais tradicionais. As estratégias de ação, os padrões de recrutamento, o perfil de seus membros e a disponibilidade de recursos desses grupos diferenciam-nos tanto de partidos políticos e sindicatos quanto de associações de bairro. A própria defesa do meio ambiente é um tema bastante novo na agenda política internacional e apesar de ter se institucionalizado por meio de 
organizações não-governamentais (ONGs) e partidos políticos mais recentemente, ainda têm sopros de inovação nas suas formas de pleitear demandas.

Finalmente, o quarto tipo de ação coletiva analisada é a participação em duas formas de protesto político, que são também formas de desobediência civil: bloqueios de trânsito e invasões de propriedades privadas. Tais formas de ação coletiva são completamente distintas da participação em grupos sociais constituídos, como os discutidos até agora. Por serem formas de desobediência civil, têm provavelmente um caráter de atuação mais temporário e menos estruturado, assim como envolvem riscos maiores à participação de seus membros. Podem, ainda, ser vistas como prejudiciais à ordem democrática estabelecida nos países latino-americanos, já que vão contra a lei, o que indica um lado da ação coletiva da sociedade civil que não necessariamente é benéfica para a sociedade (FIORINA, 1999; MORALES, DE LOS REYES \& RICH, 1999).

\section{NORMAS SOCIAIS E ENGAJAMENTO CÍVICO}

$\mathrm{O}$ argumento fundamental de um dos principais artífices da teoria do capital social é que o funcionamento de instituições democráticas é condicionado pela existência de uma sociedade civil ativa e vibrante (PUTNAM, 1993) - portanto, de uma sociedade que tenha uma grande reserva de capital social. O argumento de Putnam, no clássico Making Democracy Work, é que a região Norte da Itália tem instituições democráticas mais eficazes e consolidadas porque é melhor irrigada pelas redes de engajamento cívico que sua contraparte do Sul do país. A presença de altos níveis de mobilização coletiva acerca de temas públicos cria um círculo virtuoso de valorização de práticas democráticas e fortalecimento de instituições democráticas. A lógica do argumento de Putnam é que uma sociedade civil ativa é fundamental para o fortalecimento de uma ordem política democrática. Nessa lógica, uma sociedade organizada precede um regime democrático eficiente.

Segundo essa mesma lógica, incentivos externos, impostos de cima para baixo, para a participação em associações da sociedade civil são contraproducentes e mais onerosos do que mecanismos de mobilização espontâneos e oriundos do interesse individual ou comunitário. A cooperação interpessoal induzida pelo Estado é a antítese do capital social. Na visão de Putnam, onde há um Estado forte há pouco espaço para comunidades ativas e independentes. Instituições formais podem até gerar efeitos perversos, nãoantecipados, que debilitam uma possível propensão individual a engajar-se em movimentos sociais.

Em outras palavras, Putnam argumenta que a internalização de normas sociais que aumentam a previsibilidade de comportamentos alheios, tais como confiança interpessoal, regras de reciprocidade e tolerância a posturas diferentes, são muito mais eficazes como mecanismos de estímulo à participação em ações coletivas. $\mathrm{Ou}$ seja, em sociedades em que as normas sociais internalizadas por cidadãos estimulam a cooperação e inibem comportamentos oportunistas, aumentam as chances de participação em associações da sociedade civil. Por outro lado, a presença de um Estado forte e de instituições formais exógenas à sociedade civil tende a inibir a formação de grupos sociais independentes e ativos.

Um modelo explicativo do engajamento em associações da sociedade civil que leve em consideração os pressupostos teóricos mencionados acima deve necessariamente incluir variáveis que meçam a internalização de normas sociais propícias à formação de capital social. Mais precisamente, o primeiro conjunto de hipóteses refere-se ao impacto dos indicadores clássicos de capital social: confiança interpessoal, tolerância política e otimismo. Segundo a teoria do capital social, indivíduos que são mais confiantes uns nos outros, mais tolerantes às divergências políticas e mais otimistas quanto a seus futuros são também mais propensos a envolverem-se em distintas formas de ação coletiva porque são mais abertos à interação com estranhos (PUTNAM, 1993; 1995; USLANER, 1998; 1999).

A confiança interpessoal estimula a mobilização em torno de assuntos coletivos porque gera expectativas positivas acerca do comportamento de outros. Na essência do conceito de confiança, de acordo com vários autores, está a idéia de reciprocidade (GAMBETTA, 1988; PUTNAM, 1993; HARDIN, 1999). Uma pessoa confia em outra porque espera dela um certo tipo de atitude. Quando há confiança interpessoal generalizada, o espaço para comportamentos oportunistas é reduzido, já que tendem a prevalecer padrões 
comportamentais cooperativos. Cidadãos que confiam em outras pessoas de maneira indiscriminada estão mais propensos a envolverem-se em interações com estranhos.

A tolerância política, por sua vez, é um sinal de que um indivíduo aceita diferenças de ponto de vista e respeita posições e preferências contrárias às suas (Putnam, 1993). Um indivíduo tolerante busca conciliação e aceita conviver com visões de mundo conflitantes, ambas características importantes para quem participa em formas de ação coletiva ${ }^{2}$. Por fim, pessoas otimistas quanto ao futuro também estão mais propensas a envolverem-se em movimentos e grupos sociais pois também tendem a ver outras pessoas de maneira positiva.

Um segundo conjunto de hipóteses derivadas da teoria do capital social centra-se na idéia de que pessoas que participam de associações da sociedade civil tendem a ter mais interesse por assuntos coletivos e investem mais tempo do seu dia em atividades que incluem interação com outras pessoas. Um ponto fundamental do argumento de Putnam é que passar horas de lazer em atividades individualizadas, que não exigem interação com outras pessoas (como assistir a programas de televisão), dificultam a participação em atividades coletivas. Indivíduos que passam grande parte do seu tempo dedicados a atividades individuais são menos inclinados colaborar com projetos coletivos - Putnam expressa principalmente o impacto negativo de assistir à televisão.

Contudo, há tipos de atividades individuais que podem não necessariamente levar a uma ausência de interesse por assuntos públicos. De fato, informar-se sobre temas e notícias, por meio de jornais escritos, ou mesmo televisivos, pode fazer parte do rol de atividades desempenhadas por pessoas que tendem a participar de associações da sociedade civil. O Latinobarômetro oferece a perfeita oportunidade para testar tais hipóteses pois contém uma bateria de perguntas sobre atividades que os entrevistados desempenham em seu horário livre. São analisadas variáveis que medem tempo

\footnotetext{
2 A tolerância foi medida por meio de uma pergunta que pedia ao entrevistado para escolher quais as principais características de um regime democrático. A tolerância política é representada pela escolha de dois itens: direito de expressão e liberdade para partidos de oposição.
}

gasto assistindo a notícias na televisão, lendo jornais e praticando esportes. A prática de esportes, principalmente coletivos, como mais convincentemente argumenta Uslaner (1999), cria uma arena de interação entre indivíduos e um espaço para discussão e debate sobre os mais variados temas. Portanto, todas essas formas de passar-se o tempo devem ter um efeito positivo na participação nos distintos tipos de ação coletiva.

Uma outra medida de interesse por assuntos coletivos empregada aqui é o tempo que o indivíduo gasta conversando sobre política com amigos. Redes sociais são fundamentais para incentivar ou coibir a participação em formas distintas de ação coletiva (MCADAM, 1988; OPP \& GERN, 1993; GOULD, 1995). Redes informais de amigos e conhecidos são fundamentais para proporcionar incentivos à mobilização. Portanto, passar o tempo com amigos pode servir para aumentar a propensão a participar em projetos voltados para temas coletivos.

\section{ESTRUTURAS DE OPORTUNIDADE POLÍTICA E AÇÃO COLETIVA}

Como pôde ser visto acima, a ênfase de Putnam recai especialmente sobre atributos psicológicos e sociais que afetam as chances de participação de indivíduos em formas de ação coletiva. Contudo, o papel de instituições formais em estruturar a interação social limitando o leque de comportamentos oportunistas e servindo como fonte de informação para atores políticos é quase totalmente desconsiderada (KNIGHT, 1992; EPSTEIN \& KNIGHT, 1998). Como dito anteriormente, para Putnam qualquer tipo de interferência estatal na sociedade civil leva a prejuízos para a formação de ações coletivas independentes e eficazes. É justamente esse ponto que leva Sidney Tarrow (1994) a criticar a visão reducionista da teoria do capital social. Segundo Tarrow, o papel do Estado e o tipo de intervenção estatal não podem desconsiderar-se como fatores explicativos para o sucesso de formas independentes de ação coletiva.

Contrariamente ao que diz Putnam, o Estado pode ter papel positivo na geração de ação coletiva independente na sociedade civil. A intervenção estatal pode até mesmo estimular o ativismo cívico, principalmente quando tal intervenção diz respeito a garantir o acesso irrestrito e igualitário a um sistema legal eficiente. Instituições podem fomentar ação coletiva criando estruturas de 
oportunidade política para grupos sociais. Segundo ele, estruturas de oportunidade política "são dimensões consistentes do contexto político que podem encorajar ou desencorajar pessoas de participarem em ações coletivas" (idem, p. 18). Estruturas de oportunidade política são fatores exógenos à sociedade civil que afetam a capacidade de mobilização e recrutamento de grupos sociais. A idéia central é muito simples: quando as estruturas de oportunidade política reduzem os custos da participação, haverá mobilização social.

Segundo a literatura sobre estruturas de oportunidade política (MCADAM, MCCARTHY \& ZALD, 1996), tanto traços estáveis de estados quanto mudanças na distribuição de poder dentro de um único Estado podem afetar o surgimento de entidades da sociedade civil (GAMSON \& MEYER, 1987, p. 280-281). Portanto, há arcabouços institucionais que geram maiores incentivos para a formação de organizações civis do que outros, podendo variar tanto de país para país quanto dentro de um mesmo país em momentos históricos distintos.

Um segundo elemento da discussão sobre estruturas de oportunidade política refere-se a qual aspecto de um arcabouço institucional influencia o aparecimento de ação coletiva na sociedade civil (BROCKETT, 1991; KRIESI et alii, 1992; RUCHT, 1997). Há quatro dimensões básicas segundo McAdams (1997): abertura do sistema política, estabilidade dos alinhamentos de elite, mudanças no apoio a movimentos sociais por parte das elites e a propensão estatal para repressão.

Como o banco de dados utilizado aqui baseiase em aferições sincrônicas sobre vários países, apenas alguns aspectos das estruturas de oportunidade política puderam ser avaliadas. A única estratégia disponível, na verdade, é contrastar os desenhos institucionais distintos e os legados históricos variados entre os países latino-americanos. A falta de dados diacrônicos impossibilitam a análise de como mudanças no tempo em um único país afetam a chance de surgimento de ação coletiva; por isso, avaliar-seá como diferentes níveis de abertura política e de propensão à repressão influenciam o surgimento de modos independentes de ação coletiva na sociedade civil de países latino-americanos.

É necessário, portanto, discutir como ambientes institucionais afetam o surgimento da ação coletiva. Como foi dito acima, a participação em ação coletiva diminui quando aumentam os custos da participação (VAN DYK, 1998, p. 137). Quanto maior o risco de envolver-se em ação coletiva, mais altos são os custos. Nesse sentido, ambientes institucionais podem estimular o surgimento de ação coletiva ao coibir comportamentos oportunistas e ao reduzir os riscos para a participação. Podem também aumentar a participação gerando incentivos institucionais para o fortalecimento de grupos sociais, por meio da criação de mecanismos que permitam a esses grupos externar suas demandas - como eleições livres, por exemplo.

Para coibir comportamentos oportunistas, o Estado precisa gerar um certo nível de previsibilidade de comportamentos e expectativas, voltados para o cerceamento de atitudes que prejudiquem quem busca soluções coletivas. Para estimular a participação em formas de ação coletiva da sociedade civil, o Estado precisa indicar que está aberto à participação de grupos independentes. Conseqüentemente, regimes políticos com períodos prolongados de eleição para cargos públicos - o que é forte indicativo da abertura do Estado - e em que a lei é respeitada elemento central à redução de comportamentos oportunistas - são mais propensos à formação de movimentos civis. Regimes em que há eleições livres e sinais de que é seguro envolver-se em movimentos sociais independentes são favoráveis ao surgimento de ação coletiva na sociedade civil.

Duas variáveis foram operacionalizadas para testar o impacto da abertura do regime político e a eficiência das instituições estatais em coibir comportamentos oportunistas. A primeira é uma contagem do número de anos que um país teve eleições livres e diretas. Onde há eleições por períodos mais prolongados de tempo, há maior chance de que as instituições de representação de interesses estejam consolidadas. A presença de eleições também é um indicador potencial da ausência de repressão a movimentos independentes e de que o Estado está aberto a ouvir as demandas da sociedade.

A segunda variável é a proporção de homicídios por ano. Tal variável é um indicador da ausência de regulação eficiente por parte do Estado sobre comportamentos prejudiciais a outras pessoas. Onde a lei não é assegurada pelas instituições 
estatais há mais brechas para a prevalência de comportamentos oportunistas, que, por sua vez, aumentam os custos de interação com outras pessoas. Quando um cidadão não consegue prever, mesmo que de maneira mínima, que o cidadão ao seu lado não tirará vantagem dele em uma situação de interação entre ambos, a cooperação entre esses dois cidadãos se torna errática e improvável. Uma pessoa não se aventurará além da esfera da vida privada se não houver garantias na esfera pública que essa pessoa não será prejudicada por envolverse em um projeto comum com outros cidadãos.

Em contextos em que a lei não é respeitada e efetivamente garantida pelo Estado, a expectativa predominante da população é que para fora do círculo mais próximo de amizades e parentes o risco de ser prejudicado por outra pessoa é muito grande (SANTOS, 1993). O número de homicídios em um país é um indicador claro da extensão de comportamentos ilegais na sociedade. Onde há mais homicídios, a lei é frágil e a capacidade do Estado de fazer a lei vigorar é menor. Em ambientes em que a criminalidade é alta, não há espaço para a ação coletiva, apenas para a sobrevivência. Portanto, o índice de homicídios, na análise multivariada, deve ter um impacto negativo na propensão individual para participar em associações da sociedade civil.

Além de medir as estruturas de oportunidade política em nível agregado, uma outra forma de avaliar o impacto de instituições formais é usando avaliações de indivíduos sobre a legitimidade e a eficiência de tais instituições. Uma distinção necessária quando se fala de avaliação de instituições é entre apoio específico e apoio difuso. $\mathrm{O}$ primeiro refere-se "ao conjunto de atitudes em relação a uma instituição baseada em sua capacidade de dar resposta a demandas por uma política específica" (CALDEIRA \& GIBSON, 1992, p. 637). Já o apoio difuso relaciona-se "ao reservatório de atitudes favoráveis ou de boa vontade" referentes a uma instituição, a despeito de avaliações sobre o desempenho de tal instituição. Portanto, o apoio difuso refere-se a um apoio incondicional e mais abstrato a uma certa instituição; já o apoio específico volta-se para avaliações de desempenho.

Avaliações positivas tanto do desempenho quanto da legitimidade das instituições certamente indicam que há uma percepção de que o espaço público é regulado e, portanto, seguro. Nesse caso, altos níveis de apoios difuso e específico estimulam a mobilização pública na forma de participação em ações coletivas da sociedade civil. Contudo, a participação em movimentos de protesto político, relacionados à desobediência civil, devem ser negativamente influenciados por tais avaliações: indivíduos que participam de movimentos contestatórios necessariamente devem estar insatisfeitos com o desempenho de instituições públicas.

\section{ANÁLISE DOS DADOS}

Os quadros 1 a 3 contêm os coeficientes logit, erros-padrão e nível de significância estatística de cada variável independente nas equações que explicam a participação em grupos locais, nacionais e em movimentos ambientalistas. O Quadro 4 apresenta os coeficientes de regressão de mínimos quadrados com seus respectivos erros padrão e níveis de significância para o indicador de participação em movimentos de protesto político. Todos os modelos são estatisticamente significativos $^{3}$, mas o mais importante é avaliar o impacto de cada variável independente em cada um dos modelos por meio da análise da direção da relação, indicada pelo sinal positivo ou negativo de cada coeficiente, e se tal relação é estatisticamente significativa ou não $0^{4}$.

Em primeiro lugar é importante ressaltar que as variáveis independentes têm efeitos distintos em cada uma das equações. As motivações que levam à participação em movimentos sociais e políticos é diferente para cada tipo de movimento, o que fortalece ainda mais a idéia inicial deste artigo de que tipos diferentes de mobilização da sociedade civil não podem ser analisados como sendo um fenômeno único.

\footnotetext{
3 Como estou lidando com uma amostra que combina 16 países latino-americanos, estratificados por país, usando a estimação para amostras complexas disponíveis no programa STATA, o cálculo de variância total explicada por cada modelo não é possível. A Bolívia foi excluída da análise devido à ausência de dados relativos à taxa de homicídio.

4 A avaliação do impacto substantivo de cada variável independente também é interessante e importante. Contudo, como nas tabelas 3 a 4 foram utilizadas regressões logísticas para dados estratificados por país, devido à forma dicotômica de como as variáveis dependentes foram medidas e para corrigir a heteroscedasticidade presente nos dados, a interpretação substantiva desses coeficientes não é possível.
} 
QUADRO 1 - PARTICIPAÇÃO EM FORMAS LOCAIS DE AÇÃO COLETIVA NA AMÉRICA LATINA (1996)

\begin{tabular}{|l|c|c|}
\hline \multicolumn{1}{|c|}{ Variáveis } & Coeficientes & Erro padrão \\
\hline Confiança interpessoal & $-0,049$ & 0,05 \\
\hline Otimismo & 0,026 & 0,05 \\
\hline Tolerância & $-0,001$ & 0,04 \\
\hline Assistir a jornais na TV & 0,015 & 0,01 \\
\hline Ler jornais impressos & 0,032 & $0,008^{* * *}$ \\
\hline Praticar esportes & $-0,124$ & $0,04^{* *}$ \\
\hline Redes de amizades & $-0,198$ & $0,04^{* * *}$ \\
\hline Apoio específico & 1,014 & $0,162^{* * *}$ \\
\hline Apoio difuso & 0,131 & $0,037^{* * *}$ \\
\hline Anos contínuos de eleições & $-0,004$ & $0,001^{* * *}$ \\
\hline Taxa de homicídios & $-0,002$ & $0,000^{* * *}$ \\
\hline
\end{tabular}

FONTE: Latinobarómetro (1996).

NOTAS: $F=15,15^{* * *} ; N=15434 ; N$. de Strata = 16; * significância de 0,05, ** significância de $0,01 e^{* * *}$ significância de 0,001.

O Quadro 1 indica que a participação em formas locais de ação coletiva não é afetada por normas sociais como confiança interpessoal, otimismo e tolerância, nem assistir a jornais na televisão. O que aumenta a participação em associações locais é a leitura de jornais, avaliações positivas sobre a eficiência (apoio específico) e a legitimidade de instituições (apoio difuso). Já a participação em esportes e em redes de interação com amigos tem impacto negativo. Isso indica, na verdade, que os incentivos para participar em associações de bairro, grupos de mães e grupos de igreja independe da necessidade de obter incentivos para tal de amigos e colegas. Uma variável que apresenta resultado até certo ponto inesperado é o efeito negativo da que mede o número de eleições livres, ao longo dos anos, na participação em grupos locais. Esse resultado indica que movimentos sociais em nível local tendem a ser mais freqüentes em países que acabaram de se redemocratizar e que parece haver uma reversão desse ímpeto associativista, pelo menos no que tange a associações de bairro, de igreja e de mães, com a realização de mais eleições. Uma possível explicação é que tal ímpeto de participação em grupos locais vem a ser suplantado pela participação em grupos de âmbito nacional com a consolidação de um sistema eleitoral.

A variável proporção de homicídios apresenta um resultado negativo teoricamente previsto. Onde há mais homicídios e menos respeito à lei é mais baixa a tendência de indivíduos atuarem na esfera coletiva.

QUADRO 2 - PARTICIPAÇÃO EM FORMAS NACIONAIS DE AÇÃO COLETIVA NA AMÉRICA LATINA (1996)

\begin{tabular}{|l|c|c|}
\hline \multicolumn{1}{|c|}{ Variáveis } & Coeficientes & Erro padrão \\
\hline Confiança interpessoal & $-0,26$ & $0,08^{* *}$ \\
\hline Otimismo & 0,003 & 0,08 \\
\hline Tolerância & 0,052 & 0,07 \\
\hline Assistir a jornais na TV & 0,029 & $0,015^{*}$ \\
\hline Ler jornais impressos & 0,114 & $0,013^{* * *}$ \\
\hline Praticar esportes & 0,234 & $0,07^{* *}$ \\
\hline
\end{tabular}




\begin{tabular}{|l|c|c|}
\hline Redes de amizades & 0,102 & 0,07 \\
\hline Apoio específico & 1,91 & $0,183^{\star * *}$ \\
\hline Apoio difuso & 0,367 & $0,052^{\star \star *}$ \\
\hline Anos contínuos de eleições & 0,005 & $0,002^{\star *}$ \\
\hline Taxa de homicídios & $-0,006$ & $0,001^{\text {}}$ \\
\hline
\end{tabular}

FONTE: Latinobarómetro (1996).

NOTAS: $\mathrm{F}=36,24^{\star * *} ; N=15434 ; \mathrm{N}$. de Strata $=16$; * significância de 0,05 , ** significância de $0,01 \mathrm{e}^{* \star \star}$ significância de 0,001.

Já com relação à participação em associações políticas de âmbito nacional, partidos políticos e sindicatos, os anos de eleições livres têm o impacto positivo esperado. Portanto, parece confirmar-se a hipótese levantada acima de que com a institucionalização do sistema eleitoral, parece haver um deslocamento da participação de movimentos sociais locais para grupos políticos voltados para interesses de classe e políticos. As outras medidas de estrutura de oportunidade política - número de homicídios, apoio específico e apoio difuso - também apresentam resultados teoricamente esperados. Além disso, ler jornais, assistir a jornais na televisão e praticar esportes também aumentam a propensão a envolver-se em partidos políticos e sindicatos, confirmando, desta feita, as expectativas teóricas. Finalmente, os indicadores de capital social (confiança interpessoal, tolerância e otimismo) novamente apresentam resultados que contradizem a teoria.

A confiança interpessoal, na verdade, tem impacto negativo e estatisticamente significativo na participação em partidos políticos. Ou seja, quem tende a confiar em outras pessoas não se envolve em formas organizadas de participação política. Isso levanta a interessante hipótese de que a mobilização política pode ser gerada por uma sensação crescente de desconfiança com relação aos outros. Ou seja, pode ser que a desconfiança seja um motor para certo tipo de ação coletiva. Como partidos políticos e sindicatos são entidades de defesa de interesses específicos que invariavelmente estão envolvidos em conflitos e disputas, é compreensível que a confiança interpessoal indiscriminada não faça parte do leque de características dos membros de tais instituições.

QUADRO 3 -PARTICIPAÇÃO EM GRUPOS AMBIENTALISTAS NA AMÉRICA LATINA (1996)

\begin{tabular}{|l|c|c|}
\hline \multicolumn{1}{|c|}{ Variáveis } & Coeficientes & Erro padrão \\
\hline Confiança interpessoal & 0,145 & 0,092 \\
\hline Otimismo & 0,171 & 0,111 \\
\hline Tolerância & 0,194 & $0,08^{*}$ \\
\hline Assistir a jornais na TV & 0,017 & 0,017 \\
\hline Ler jornais impressos & 0,075 & $0,017^{\text {** }}$ \\
\hline Praticar esportes & 0,424 & $0,09^{\text {***}}$ \\
\hline Redes de amizades & 0,117 & 0,08 \\
\hline Apoio específico & 0,989 & $0,220^{\text {*** }}$ \\
\hline Apoio difuso & 0,200 & $0,068^{* *}$ \\
\hline Anos contínuos de eleições & 0,009 & $0,002^{\text {** }}$ \\
\hline Taxa de homicídios & 0,001 & 0,001 \\
\hline
\end{tabular}

FONTE: Latinobarómetro (1996).

NOTAS: $F=15,72^{* * *} ; N=15434 ; N$. de Strata $=16$; * significância de $0,05,{ }^{* *}$ significância de $0,01 e^{* * *}$ significância de 0,001 . 
Com relação à participação em grupos de defesa do meio ambiente, como nos demais modelos, as variáveis "apoio institucional" e "anos de eleição", assim como passar tempo praticando esportes e lendo jornais, são as que apresentam coeficientes estatisticamente significativos e positivos. A grande diferença é que agora um dos indicadores da internalização de normas sociais que fomentam o capital social é estatisticamente significativa e positiva: a tolerância para com posturas políticas distintas aumenta a probabilidade de participar de movimentos de proteção ao meio ambiente. Isso confirma a idéia de que tais movimentos têm um caráter suprapartidário e que normalmente são compostos por pessoas abertas ao debate político.

QUADRO 4 - PARTICIPAÇÃO EM GRUPOS DE PROTESTO POLÍTICO NA AMÉRICA LATINA (1996)

\begin{tabular}{|l|c|c|}
\hline \multicolumn{1}{|c|}{ Variáveis } & Coeficientes & Erro padrão \\
\hline Confiança interpessoal & 0,021 & 0,010 \\
\hline Otimismo & $-0,019$ & $0,009^{*}$ \\
\hline Tolerância & 0,017 & $0,008^{*}$ \\
\hline Assistir a jornais na TV & 0,003 & 0,001 \\
\hline Ler jornais impressos & 0,003 & $0,001^{*}$ \\
\hline Praticar esportes & 0,061 & $0,01^{* * *}$ \\
\hline Redes de amizades & 0,058 & $0,009^{* * *}$ \\
\hline Apoio específico & 0,015 & 0,032 \\
\hline Apoio difuso & 0,011 & 0,006 \\
\hline Anos contínuos de eleições & 0,002 & $0,0002^{* * *}$ \\
\hline Taxa de homicídios & 0,0003 & $0,0001^{* * *}$ \\
\hline
\end{tabular}

FONTE: Latinobarómetro (1996).

NOTAS: $F=18,50^{* * *} ; N=14723 ; \mathrm{N}$. de Strata $=16 ;{ }^{*}$ significância de $0,05,{ }^{* *}$ significância de $0,01 e^{* * *}$ significância de 0,001 .

Também com relação à participação em movimentos políticos de protesto a variável tolerância política tem impacto positivo. Isso indica também que aqueles que participam de movimentos políticos de protesto aceitam o direito de existência de partidos políticos de oposição. Já o otimismo não é uma característica de quem participa desses movimentos, como indica o coeficiente negativo e estatisticamente significativo dessa variável. Isso é compreensível, já que movimentos de protesto políticos são motivados também por falta de perspectivas positivas com relação ao futuro.

A rede de contatos individuais (passar o tempo conversando com amigos) também tem impacto positivo na participação em movimentos de protesto. Parece confirmar-se a hipótese de que esse tipo de participação política, que envolve riscos, aumenta quando um indivíduo é motivado a participar por um grupo de amigos e colegas. $\mathrm{O}$ risco de participação também é diminuído pelos anos de eleições livres. Em regimes democráticos mais duradouros, os cidadãos sentem-se mais livres, menos reprimidos, e por isso tendem a envolver-se mais em formas de protesto.

Outra variável que apresenta resultado interessante é o índice de homicídios. Em países onde o índice de homicídios é alto, há mais participação em formas de protesto político. Isso indica que em países onde há menos respeito à lei, onde as instituições de repressão do Estado são, consequientemente, mais frágeis, os riscos para a participação em protestos políticos são também menores. Portanto, indivíduos que querem praticar desobediência civil sentem-se mais encorajados a proceder dessa forma.

\section{CONCLUSÃO}

Foram testadas, neste artigo, duas explicações distintas para entender porque as pessoas mobilizam-se em formas diferentes de ação coletiva na sociedade civil. O objetivo foi avaliar 
como cada uma dessas explicações contribui para o melhor entendimento do surgimento de associações da sociedade civil. De modo geral, as variáveis relacionadas à idéia de capital social (confiança interpessoal, tolerância e otimismo) apresentaram resultados mais inconsistentes e efêmeros do que as variáveis que medem o impacto das estruturas de oportunidade política, confirmando estudos anteriores sobre a América Latina, como os de Booth e Richard (1998) e Seligson (1999). Ainda no caso da América Latina, parece que o arcabouço institucional de cada país, assim como a percepção individual sobre o funcionamento de tais instituições, é um determinante mais forte da participação em associações da sociedade civil do que a internalização de normas sociais como confiança interpessoal ou otimismo.

O que aparentemente condiciona o ativismo da sociedade civil nesses países é muito mais a existência de aberturas e garantias oferecidas por instituições formais do que os indicadores de capital social. Portanto, o Estado e a ordem estabelecida externamente à sociedade civil têm um importante impacto no próprio fortalecimento da sociedade civil. Obviamente, não se trata de um Estado que crie, por si próprio, movimentos sociais, ou que os coopte. Trata-se, sim, de um Estado que limite a prevalência de comportamentos oportunistas dessa forma gerando incentivos indiretos ao fortalecimento de movimentos sociais independentes.

Lucio R. Rennó (lurst2@pitt.edu) é doutorando em Ciência Política na University of Pittsburgh (EUA).

\section{REFERÊNCIAS BIBLIOGRÁFICAS}

ALMOND, G. \& VERBA, S. (eds.). 1980. The Civic Culture Revisited. Boston : Little Brown.

BOOTH, J. \& RICHARD, P. 1998. Civil Society, Political Capital, and Democratization in Central America. Journal of Politics, v. 60, n. 3, p. 780-800, Aug.

BROCKETT, C. 1991. The Structure of Political Opportunities and Peasant Mobilization in Central America. Comparative Politics, New York, v. 23, n. 3, p. 253-274, Apr.

CALDEIRA, G. \& GIBSON, J. 1992. The Etiology of Public Support for the Supreme Court. American Journal of Political Science, v. 36, n. 36, p. 635- 664, Aug.

EPSTEIN, L. \& KNIGHT, J. 1998. The Choices Justices Make. Washington, D. C. : CQ Press.

FIORINA, M. 1999. Extreme Voices : A Dark Side of Civic Engagement. In : SKOCPOL, T. \& FIORINA, M. (eds.). Civic Engagement in American Democracy. Washington, D. C. : Brookings Institution.

GAMBETTA, D. 1988. Can We Trust Trust? In : (ed.) Trust : Making and Breaking Cooperative Relations. London : Basil Blackwell.

GAMSON, W. \& MEYER, D. 1997. Framing
Political Opportunity In : MCADAM, D., MCCARTHY, J. D. \& ZALD, M. (eds.). Comparative Perspectives on Social Movements : Political Opportunities, Mobilizing Structures, and Cultural Framings. Cambridge : Cambridge University Press.

GOULD, R. 1995. Insurgent Identities : Class, Community and Protest in Paris from 1848 to the Commune. Chicago : University of Chicago Press.

HARDIN, R. 1999. Do We Want Trust in Government? In : WARREN, M. (ed.). Democracy and Trust. Cambridge : Cambridge University Press.

KNIGHT, J. 1992. Institutions and Social Conflict. Cambridge : Cambridge University Press.

KRIESI, H., KOOPMANS, R., DUYVENDAK, J. W. \& GIUGNI, M. G. 1992. New Social Movements and Political Opportunities. Western Europe, n. 22, p. 219-244.

LAGOS, M. 1997. Latin America's Smiling Face. Journal of Democracy, Baltimore, v. 8, n. 3, p. 125-138, July.

LEVINE, D. \& MAINWARING, S. 1994. Religion and Popular Protest in Latin Ame- 
rica : Contrasting Experiences. In : ECKSTEIN, S. (ed.). Power and Popular Protest : Latin American Social Movements. Los Angeles : University of California Press.

MCADAM, D. 1988. Micromobilization Contexts. In : KLANDERMANS, K, KRIESI, J \& TARROW, S. (eds.). From Structure to Action : Comparing Social Movement Research Across Cultures. International Social Movement Research I. s/l : Jai Press.

1997. Conceptual Origins, Current Problems, Future Directions. In : MCADAM, D., MCCARTHY, J. D. \& ZALD, M. (eds.). Comparative Perspectives on Social Movements : Political Opportunities, Mobilizing Structures, and Cultural Framings. Cambridge : Cambridge University Press.

MCADAM, D., MCCARTHY, J. D. \& ZALD, M. (eds.). 1996. Comparative Perspectives on Social Movements : Political Opportunities, Mobilizing Structures, and Cultural Framings. Cambridge : Cambridge University Press.

MORALES, I., DE LOS REYES, G. \& RICH, P. (eds.). 1999. Civil Society and Democratization. Special Issue of The Annals, London, v. 565, Sept.

NORTH, D. 1995. Institutions, Institutional Change, and Economic Performance. Cambridge : Cambridge University Press.

OLSON, M. 1965. The Logic of Collective Action. Cambridge : Harvard University Press.

OPP, K. \& GERN, C. 1993. Dissident Groups, Personal Networks and Spontaneous Cooperation : the East German Revolution of 1989. American Sociological Review, Madison, n. 58, n. 5 , p. $659-680$.

PUTNAM, R. 1993. Making Democracy Work: Civic Traditions in Modern Italy. Princeton : Princeton University Press.

.1995a. Bowling Alone : America's Declining Social Capital. Journal of Democracy, Baltimore, v. 6, n. 1, p. 65-78, Jan.

1995b. Tuning In, Tuning Out : The Strange Disappearance of Social Capital in America. PS : Political Science and Politics, Cambridge, v. 27, n. 4, p. 664-683, Oct.
ROTHSTEIN, B. 2000. Trust, Social Dilemmas and Collective Memories. Journal of Theoretical Politics, Thousand Oaks, v. 12, n. 4, p. 477-501, Oct.

RUCHT, D. 1997. The Impact of National Contexts on Social Movement Structures : A Cross-Movement and Cross-national Comparison $I n$ : MCADAM, D., MCCARTHY, J. D. \& ZALD, M. (eds.). Comparative Perspectives on Social Movements : Political Opportunities, Mobilizing Structures, and Cultural Framings. Cambridge : Cambridge University Press.

SANTOS, W. G. 1993. Razões da desordem. Rio de Janeiro: Rocco.

SELIGSON, A. 1999. Civic Association and Democratic Participation in Central America : A Test of the Putnam Thesis. Comparative Political Studies, Thousand Oaks, CA, v. 32, n. 3, p. 342-362, July.

TARROW, S. 1994. Power in Movement : Social Movements, Collective Action and Politics. Cambridge : Cambridge University Press.

. 1996. Making Social Science Work Across Space and Time : A Critical Reflection on Putnam's Making Democracy Work.. American Political Science Review, Cambridge, v. 90 , n. 2, p. 389-397, June.

TOURAINE, A. 1985. An Introduction to the Study of Social Movements. Social Research, New York, v. 52, p. 749-788.

USLANER, E. M. 1998. Social Capital, Television, and the "Mean World" : Trust, Optimism, and Civic Participation. Political Psychology, v. 19, n. 3, p. 441-468, Sept.

1999. Democracy and Social Capital. In : WARREN, M. (ed.). Democracy and Trust. Cambridge : Cambridge University Press.

VAN DYK, R. 1998. The Pro-Choice Legal Mobilization and Decline of Clinic Blockades. In : SCHULTZ, D. (ed.) Leveraging the Law : Using the Courts to Achieve Social Change. New York : Peter Lang.

VERBA, S., SCHLOZMAN, K. \& BRADY, H. 1996. Voice and Equality : Civic Voluntarism in American Politics. Cambridge, Mass. : Harvard University Press. 
ZALD, M. \& MCCARTHY, J. (eds.). 1994. Social Movements in an Organizational Society. New Brunswick : Transaction Publishers.

WORLD BANK. 1997. Crime and Violence as
Development Issues in Latin America and the Caribbean. Washington, D. C. : The World Bank Group.

1998. World Development Indicators. Washington, D. C. : The World Bank Group.

\section{APÊNDICE}

\section{Variáveis independentes:}

Variáveis dicotômicas: assistir a jornais na televisão, ler jornais, praticar esportes, passar o tempo com amigos, otimismo, confiança interpessoal e tolerância política.

$\mathrm{O}$ apoio difuso foi medido por meio de um índice composto por uma escala de 7 categorias indicando confiança no Congresso, Judiciário, burocracia, polícia, exército, partidos políticos e governo. Cronbach's Alpha de 0,87.

$\mathrm{O}$ apoio específico foi medido por meio de um índice composto por 6 escalas de quatro categorias indicando confiança em atores que representam instituições democráticas, incluin- do juízes, policiais, servidores públicos, políticos, militares e congressistas. Cronbach's Alpha de 0,84 .

\section{Indicadores de estruturas de oportunidades política:}

Os anos de eleições são uma contagem dos anos em que um país tem ininterruptamente eleições livres.

A taxa de homicídios é uma contagem aproximada de homicídios por 100000 habitantes. Sua fonte é a PAHO - Pan-American Health Organization, Health Situation Analysis Program, citada no relatório do Banco Mundial (WORLD BANK, 1997). 